Ouwehand, E., Wong, K., Boeije, H., Braam, A. Revelation, delusion or disillusion: subjective interpretation of religious and spiritual experiences in bipolar disorder. Mental Health Religion and Culture: 2014, 17(6), 615-628

nivel

\begin{tabular}{|l|l|}
\hline $\begin{array}{l}\text { Postprint } \\
\text { Version }\end{array}$ & 1.0 \\
\hline $\begin{array}{l}\text { Journal website } \\
\text { Pubmed link }\end{array}$ & $\underline{\mathrm{http}: / / \mathrm{w} w \mathrm{w} . \text { tandfonline.com/doi/abs/10.1080/13674676.2013.874410\#.VouSd01I }}$ \\
\hline DOI & $10.1080 / 13674676.2013 .874410$ \\
\hline
\end{tabular}

This is a NIVEL certified Post Print, more info at http://www.nivel.eu

\title{
Revelation, delusion or disillusion: subjective interpretation of religious and spiritual experiences in bipolar disorder
}

\author{
EVA OUWEHAND ${ }^{\mathrm{A} *}, \mathrm{KWOK}_{\text {WONG }}^{\mathrm{B}}$, HENNIE BOEIJE $^{\mathrm{C}}$ AND ARJAN BRAAM ${ }^{\mathrm{D}, \mathrm{E}}$
}

aGeestelijke Verzorging, Altrecht, Vrijbaan 2, 3705 WC Zeist, The Netherlands; bDepartment of Bipolar Policlinic Outpatient, Altrecht, Lange Nieuwstraat 119, 3512 PG, Utrecht, The Netherlands;

cDepartment of Methodology and Statistics, Faculty of Social Sciences, University of Utrecht, PO BOX 80140, 3501 TC Utrecht, The Netherlands;

dDepartment of Emergency Psychiatry and Department of Specialist Training, Altrecht, Lange Nieuwstraat 119, 3512 PG Utrecht, The Netherlands;

eDepartment of Humanist Counseling, University of Humanistic Studies, PO BOX 797, 3500

AT Utrecht, The Netherlands

The objective of this study is to explore the interpretation of religious and spiritual experiences during mania, depression and recovery, from the perspective of bipolar clients and to inquire into their expectations of treatment in relation to these experiences. For this purpose, a qualitative pilot study is designed, which includes interviews with 10 outpatients of Altrecht, a Dutch mental health institution. The meaning of religious and spiritual experiences and the question of their authenticity proved to be an important theme for the participants. The support of spirituality for illness management was brought to the fore, as well as the temporary lack of this support during depression by some participants.

Participants considered it desirable that more attention be paid to the topic during treatment, and to establish better cooperation between spiritual counsellors of the institution and other professionals. Thus, a more existential or hermeneutical approach towards religious experiences in relation to bipolar disorder would be a desirable contribution to standard treatment. The exact outlines of such an approach demand more empirical research.

\section{INTRODUCTION}

Recently published meta-analyses (Braam, 2009; Pesut, Clark, Maxwell, \& Michalak, 2011) on the relationship between bipolar disorder and religion or spirituality give a varied picture of this relationship. Some studies focus on the prevalence of strong religious convictions or spiritual experiences in bipolar clients, or on religious delusions during mania. In others, religious coping and illness 
Ouwehand, E., Wong, K., Boeije, H., Braam, A. Revelation, delusion or disillusion: subjective interpretation of religious and spiritual experiences in bipolar disorder. Mental Health Religion and Culture: 2014, 17(6), 615-628

management are the central point. Pesut et al. (2011) observe a dichotomy between studies that focus attention on psycho-pathology and others that highlight religion or spirituality as a resource. The focus of the current study is on the relation between religion or spirituality and bipolar disorder from a client-centred perspective. The concepts "religion" and "spirituality" are the subject of much discussion, and no general agreement about their meaning has been established (Huguelet \& Koenig, 2009; Spilka, Hood, Hunsberger, \& Gorsuch, 2003). The secularisation thesis which announced the gradual disappearance of religion from the Western stage, is increasingly criticised in the Social Sciences and replaced by the concept of "transformation" of religion. Some authors see "religion" as referring to transcendental authority and traditional institutions and as such diametrically opposed to "spirituality" which is seen as being more closely related to personal life and expression (Woodhead, Heelas, Seel, Szerszynski, \& Tusting, 2005). In contrast to this, Kronjee and Lampert (2006) do not make a conceptual difference between spirituality and religion, but focus on lifestyle instead.

They distinguish between "bound" spirituality or religion when people count themselves as belonging to a religious group or institution $(28 \%$ of the Dutch population), and "unbound" spirituality or religion when people do not, but still regard themselves as religious or spiritual ( $26 \%$ of the Dutch population). For our research, we consider it a feasible approach to take the participants' own judgement about their belonging to a religion or otherwise as a starting point. This means we do not define religion or spirituality in advance and use the words religion and spirituality interchangeably.

Studies that investigate religious experiences such as conversion and mystical union in bipolar clients conclude that prevalence of these experiences amounts to $52 \%$ of 62 participants (Gallemore, Wilson, \& Rhoads, 1969), or 55\% in a sample of inpatients of whom 11 were in a manic episode (Kroll \& Sheenan, 1989). Mitchell and Romans (2003) found a strong religious belief in $79 \%$ of their sample of New Zealanders with bipolar disorder in a euthymic state. Starting from the perspective of the pathology, the prevalence of religious content in manic delusions differs substantially in studies, varying across studies from 15\% to 31\% (Applebaum, Robbins, \& Roth, 1999; Cothran \& Harvey, 1986; Getz, Fleck, \& Strakowski, 2001). The conclusion from these various figures is that religion is an important issue for some clients with bipolar disorder.

In a large Canadian health survey, higher spiritual values (e.g., search for meaning, giving strength, understanding life's difficulties) were associated with higher odds of having current and past depression and mania (Baetz, Boven, Jones, \& Koru-Sengul, 2006). According to the authors, this association might reflect the use of religious coping when faced with life difficulties as mental disorders. Mitchell and Romans (2003) in their study present a refined picture of religious coping. They examined, for example, different ways of practising belief (in an organisational or in a more private way), and how these were related to views on illness management and health outcomes. Although participants regarded spiritual healing as helpful, this was not related to better health outcomes. Forty per cent of the participants in this New Zealand study reported a decrease of faith because of bipolar disorder. In several empirical studies that investigated clients' expectations of treatment with regard to spirituality and religion (Baetz, Griffin, Bowen, \& Marcoux, 2004; Fitchett, Burton, \& Sivan, 1997; Pieper \& van Uden, 2005; Seyringer et al., 2007), mental 
Ouwehand, E., Wong, K., Boeije, H., Braam, A. Revelation, delusion or disillusion: subjective interpretation of religious and spiritual experiences in bipolar disorder. Mental Health Religion and Culture: 2014, 17(6), 615-628

health-care clients considered religion or worldview as relevant to their mental nivel problems and treatment. In the only qualitative study which specifically focussed on quality of life of clients with bipolar disorder, spirituality emerged as an important aspect of the quality of life for one-third of the 35 interviewed patients (Michalak, Yatham, Kolesar, \& Lam, 2006). The question whether religious experience was "real" or a sign of hyper-religiosity was a theme for many patients. The impact of bipolar disorder on religious involvement in their community was another one. Spirituality showed complex connections with social support, routine, stigma and disclosure. For example, ostracism by their religious community simultaneously implied loss of social support and the loss of routine of religious activity.

To obtain more insight in this perceived importance of religion and spirituality among clients with bipolar disorder, the current pilot study is intended to examine the following research questions:

(1) How do clients with bipolar disorder evaluate their experiences during mania and depression while they are in a euthymic state?

(2) How do these evaluations influence their perceptions of life and illness?

(3) What do clients expect of treatment with regard to their religiousness or spirituality?

The aim of this pilot study is to identify important themes for clients with bipolar disorder in relation to the spiritual and religious experiences they have. It covers a small sample because it is meant as a starting point for further research to improve clinical practice in a way that reckons with the clients' perspective.

\section{METHODS}

\section{Recruitment and sample}

The study was initiated in Altrecht, a mental health institution in the city of Utrecht and its immediate environment, in the Netherlands, that also includes a specialist centre for bipolar disorder.

Little literature about the content of religious or spiritual experiences related to the disorder is available. Standard psychiatric treatment usually does not focus on the content of experiences that are considered manic or psychotic. For exploration and description of a hitherto virtually unknown field, a qualitative research design is appropriate (Boeije, 2010). As mentioned before, Pesut et al. (2011) pointed out the dichotomy in the literature between an approach of religion from a psychopathological and from a "religion as resource" angle. Therefore, a phenomenological- hermeneutical approach was used. Phenomenologicalhermeneutical qualitative research is, on the one hand, philosophically rooted in the phenomenological tradition which describes phenomena as richly as possible to come to their essence or quintessential meaning (Creswell, 2007). Hermeneutics, on the other hand, does not seek the essentials of phenomena, but implies that every process of understanding starts from a particular position (Swinton \& Mowat, 2006). There is always pre-understanding which directs interpretation of experience. Hermeneutics was originally the discipline of understanding classical (theological) texts, but during the last decennia it has also been applied to human expressions in general (Dingemans, 1991), or to the interpretation of life stories as "living human documents" (Gerkin, 1984) in pastoral counselling.

The hermeneutic approach in this study implies that the interpretation of religious experience from a client-centred perspective has been brought into a dialogue with 
Ouwehand, E., Wong, K., Boeije, H., Braam, A. Revelation, delusion or disillusion: subjective interpretation of religious and spiritual experiences in bipolar disorder. Mental Health Religion and Culture: 2014, 17(6), 615-628

the theological and medical professional framework of the researchers. The phenomenological-hermeneutical approach is in its basic assumptions similar to the interpretative phenomenological analysis in psychology (Biggerstaff \& Thompson, 2008; Brocki \& Wearden, 2006).

This pilot study, which includes 10 bipolar outpatients of Altrecht, is intended as a first exploration of the research questions. Five participants were approached by the first author, a spiritual counsellor; of these five, four were known from previous counselling contact. The other five were recruited by the staff of the ambulant department for bipolar disorder. Those individuals the staff judged might be interested, were approached. The sample characteristics are listed in Table 1. It appeared to be easier to recruit participants who were known by the spiritual counsellor than via other staff members. The reason for this could be that spirituality was not always a topic during treatment. During hospital admission, clients often contact the spiritual counsellor themselves and these contacts are not part of the treatment. All interviews were conducted by the first (spiritual counsellor) and second author (resident psychiatrist under training) together. The second author was not acquainted with any of the participants.

\section{[TABLE 1]}

The participants in this study were all raised in the Christian tradition. Six were raised within the tenets of a Protestant Church and four within those of the Roman Catholic Church. At the time of the interview, five participants were still Christian, four participants referred to a form of New Age Spirituality, not bound to any religious group, and one participant considered himself as not religious anymore, though he practised Zen-meditation.

\section{Ethics}

Participants were informed about research aims and procedure by telephone and mail. This information was again presented at the beginning of the interview. The consent forms were signed at the end of the interview, together with the filling in of the forms to assess that participants had recovered. The researchers chose this moment to influence the interviews as little as possible by concepts of mental illness and encourage spontaneous reaction to the questions. None of the participants were clients of the authors at the time of the interview. The fact that four participants had had previous counselling contact with one of the researchers was recorded in the research proposal. The study was approved by the Scientific Committee of Altrecht Mental Health Care, which assesses all research proposals on ethical standards.

\section{Data collection}

The 10 participants were interviewed for approximately 1.5 hours. The interviews were semistructured.

Topics of the interview were: (1) Religious upbringing and present religious/spiritual attitude.

(2) Duration of the illness.

(3) Spiritual/religious experiences during mania and depression.

(4) Evaluation of these experiences at the time of the interview.

(5) General reflections on the relationship between spirituality and bipolar disorder.

(6) Experiences with and expectations from mental health-care professionals in relation to spirituality/religion. 
Ouwehand, E., Wong, K., Boeije, H., Braam, A. Revelation, delusion or disillusion: subjective interpretation of religious and spiritual experiences in bipolar disorder. Mental Health Religion and Culture: 2014, 17(6), 615-628

Before the interview took place, a clear explanation was given of the aim of the nivel research and the role of the interviewers. We used a flexible format for interviewing and participants were invited to raise their own topics and give tips to improve treatment. To assess whether clients were currently in a euthymic state, we administered the Altman Self-Rating Mania (ASRM) Scale (Altman, Hedeker, Peterson \& Davis, 1997), the Quick Inventory of Depressive Symptomatology - Self Report (QID-SR; Rush et al., 2003), and the Clinical Global Impressions Scale for use in bipolar illness (CGI-BP; Spearing, Post, Leverich, Brandt \& Nolen, 1997). There were no manic symptoms found (ASRM scores, $0-4$ ) and no or light depressive symptoms (QIDS-SR scores, 1-8) in the participants. The resident psychiatrist under training observed no marked mood episode by using CGI-BP (scoring of M1, D1-2).

\section{Data analysis}

Nine interviews were audiotaped and transcribed verbatim and one interview was written down verbatim during the interview, because the participant did not consent to audiotaping. The interview texts were sent to the participants with the possibility of providing a complementary commentary, of which no use was made. The text was coded with the program NVivo. The authors started coding the same interview independently and composed a common code list. After coding the following five interviews, the common code list was adjusted and interviews were coded accordingly.

The topic list was a starting point for the code tree, but sub-codes emerged from the interview texts.

Much discussion was spent on the distinction between statements that focussed on the experiences themselves to be able to describe them, and interpretative statements afterwards. The religious experiences, for example, were categorised in experiences during mania and during depression and after that coded according to the content emerging from the text (Table 2).

To give an example of the coding process: the main code "interpretation of religious experiences" was divided into the codes: "changing awareness during different phases", "cherishing", "disappointment afterwards", "approval afterwards", "doubt authenticity", "validation by others", "deepening spirituality", and "seduction \& flight". The main code "treatment relationship" was divided into the codes: "fear for reductionism", "need \& expectations", "negative treatment experiences", "positive treatment experiences", and "tips". Another point of discussion was the interrelatedness between spiritual outlook, religious development and religious experience in general and the specific role bipolar disorder played. It was not the researchers' intention to extensively relate individual experiences to the biography of the participants and present their life stories. They rather intended to explore important themes in the process of interpreting challenging spiritual experiences related to bipolar disorder and the possible contribution treatment can make in this process.

The first author made a first draft of the results. The number of quotes within a theme, the importance participants attached to a theme and contrasting experiences of participants were leading for the research report. This was discussed with the second author and adjusted. The process as a whole was discussed with a senior researcher, but no reliability audit was administered. 
Ouwehand, E., Wong, K., Boeije, H., Braam, A. Revelation, delusion or disillusion: subjective interpretation of religious and spiritual experiences in bipolar disorder. Mental Health Religion and Culture: 2014, 17(6), 615-628

\section{[TABLE 2]}

\section{RESULTS}

We start this section with a short delineation of the general remarks participants made about their religious outlook and upbringing, in order to provide a context in which the other findings can be interpreted. Subsequently, three themes that are directly related to religious experiences and their interpretation will be outlined: (i) religious experiences during mania and depression; (ii) the quest for meaning and the authenticity of the experiences and (iii) cherishing of blissful experiences.

Finally, we examine the support offered by spiritual practice in the management of illness and clients' expectations treatment and of cooperation between spiritual counsellors and other professionals.

\section{Religious outlook of the participants}

All participants were originally from a Christian background. We discovered that changes in spiritual outlook were related to life stage (puberty) or important life events, for example, the death of a relative. The onset of bipolar disorder or a manic episode could be one of them. An example of the intertwinement of life course, spiritual development and bipolar disorder was the narrative of an orthodox Protestant woman. During adolescence she discovered that she was a lesbian. After this discovery, spirituality faded into the background for her, till, years after the diagnosis of bipolar disorder, she underwent mindfulness training. Then she became interested in its Buddhist background which helped her to understand her illness (P6, New Age Spirituality). Religious involvement was fluctuating in different life episodes of the participants and was only in some cases directly related to the onset or development of the disorder.

With the exception of one participant, all participants experienced religion or spirituality as a source of confidence and support at the moment of the interview.

Religion helped them to deal with life's difficulties, of which bipolar disorder was only one. Their religious frame of reference offered them a vision on the tragedies of life in general in which things did not happen in vain.

Half of the participants mentioned they had the feeling that their life was "governed" by God or some other universal principle, or had the feeling that they were

"spiritually growing" in a direction they were drawn to. This sense of being governed could be under strain due to bipolar disorder, as in the case of the man who could not fulfil his vocation as a minister because of his illness (P3, Protestant).

We found that five participants had been studying theology or general religious/philosophical studies for some years. This indicates the high religious involvement of some of the participants.

Overall, we can say that for most participants religion was an important issue, which took different shapes in the course of their lives. Bipolar disorder was only one factor of influence in their spiritual development.

\section{Religious experiences during mania and depression}

Many participants reported intense spiritual experiences during mania, accompanied by feelings of happiness or freedom. Mystical experiences of a sense of unity, of enlightenment, of the ascending of the soul or of the presence of the divine were reported. Others mentioned seeing intense light or angels, and communication with the deceased. Changed perception of time and changed perception with respect to 
Ouwehand, E., Wong, K., Boeije, H., Braam, A. Revelation, delusion or disillusion: subjective interpretation of religious and spiritual experiences in bipolar disorder. Mental Health Religion and Culture: 2014, 17(6), 615-628

sight, hearing and smelling occurred. Insight into the deeper connections of the universe, creation or the Bible and having a divine or spiritual mission for the world were other experiences reported. Some of these experiences occurred in stable periods as well, although less intensely and for a shorter period of time. They seemed to be described on a sliding scale of religious experiences that happened during different states.

P7, for example, declared, that she got in to contact with an "in-between-dimension" between the terrestrial and the celestial dimension for the first time during her first period of mania, the consciousness of which never left her from then on (P7, Protestant).

During depression, less religious or spiritual experiences were reported. Experiences participants did mention were an absence of light or of God, an inability to reach God, an absence of meaning, coherence or goal in life, or an intense emptiness. Three reported a presence of evil forces that were physically perceptible. Three participants of orthodox Protestant background struggled with feelings of guilt, failure and punishment. Despite these negative experiences, participants emphasised that belief or spirituality supported them during depression: P5, for example, felt a "presence" during depression about which she wrote in her diary, even if it were only a few words (P5, New Age Spirituality). Another participant sometimes suddenly experienced a deep inner rest in periods of great despair, even to the extent of the appearance of Jesus at the moment she wanted to commit suicide (P7, Protestant). Two participants experienced an absolute absence of spirituality during depression: "For eighteen months it was a time without God, an absolute rock bottom, nothing at all", said one woman (P1, Protestant).

\section{The quest for meaning and the authenticity of the experiences}

To make sense of their religious experiences during mania, participants searched for an explanation within or beyond their present religious orientation. For some, the quest for meaning began after the religious experience they had had during their first manic episode, or during subsequent episodes. It manifested itself by seeking another church or reading books which could make these religious experiences comprehensible. P1 (Protestant) talks about her confusion after the first manifestation of bipolar disorder. She was an active member of the Baptist church and was studying theology. While she was writing her thesis, she had an intense experience of the presence of God. Apparently, a mania was developing, she reported. She went to an Evangelical church because in her own congregation similar religious experiences were never discussed.

Then she was hospitalised in a psychiatric clinic. Talking with another patient with "religious delusions" drove her to the conclusion that her own experience must also have been an indication of insanity. From that moment on, she decided to stop being involved in religious matters.

For most participants, an internal dialogue about the authenticity of their religious experiences had taken place after manic episodes. For some, it was still an issue at the time of the interview.

For some participants, the "insights" they had developed during manic states appeared muddled when they had recovered. For others, experiences in the manic state could be luminous or meaningful in origin, but became grotesque, distorted or exaggerated because of "the manic drive". 
Ouwehand, E., Wong, K., Boeije, H., Braam, A. Revelation, delusion or disillusion: subjective interpretation of religious and spiritual experiences in bipolar disorder. Mental Health Religion and Culture: 2014, 17(6), 615-628

One participant (P7, Roman Catholic), who was very interested in mysticism, hesitated to interpret his mystical experiences during mania as "hallel" (Hebrew for praising God), or "gallel" (Hebrew for blasphemy). He called them "psychotic" and "meaningful" or "true human experience" at the same time. He considered his interest in mysticism as a flight from the disappointments of life and originated in a desire to be special. At the same time, finding inner peace was a much more important religious goal for him than feeling good or special.

Such an internal dialogue had not come to an unambiguous conclusion for some participants and was still described as troublesome by them. After 12 years, P1 still pondered how much weight she should give to her intense experience of God's presence during her first manic episode: I never would have wanted to miss this experience. I find it hard. God was with me there, through everything. For years I had the feeling: this is important, I must write everything down. But considering what the costs are: not being able to finish my studies, three years of my life, than the question arises: does this divine encounter make up for all the losses? (P1, Protestant) For P6 in contrast, the manic state connected her to her "vocation as a human being". She was influenced by the ideas of Eckhart Tolle, a contemporary spiritual teacher whose books like "The Power of Now" are very popular, and meditation was a way of life for her: The reason why I am on earth is to Be with a capital "B" and to help people remember the divine spark within themselves. Everybody can switch over from doing to Being. When I am stable, I just do not dare to say this aloud but during a manic period I do, because I am less inhibited. (P6, New Age Spirituality) Two participants had no doubt about the genuineness of their spiritual experiences, because they regarded them as a turning point in their lives. These experiences had come after an intense religious quest as a "revelation" for the one (P4, woman, Protestant). For the other, it had come as "enlightenment" after a period of intensive psychotherapy (P2, man, New Age Spirituality).

For both they had led to important choices and a change of lifestyle. P2 judged his religious experience during mania with practical standards: I have been struggling with it for some time, so as to say: what do these experiences mean? But what makes the difference? They were pleasant, they have led to a good result and a change in myself, so just call them by whatever you like. My conclusion is: it does not make any difference. One would call it psychosis, the other enlightenment. Even among experts there is a lot of hubble-bubble.

The intense involvement in reading spiritual literature to comprehend his experience gradually decreased after his life had settled again, because in his eyes the most important existential questions had been answered.

Negative religious experiences during depression likewise brought about consideration afterwards.

P6 (New Age Spirituality) told us that concepts like "sin" and "devil", which originated from her orthodox Protestant background, came to the fore during depressive states. After recovery, she interpreted them as invented by men. Others submitted a link between orthodox protestant background and their feelings of $\sin$ and guilt during depression as well, both in their own lives as well as in the lives of other clients they had met. They mentioned it as an important theme for reflection in treatment. P5, who had macabre thoughts about her family during depression, which she interpreted as "diabolic", stressed the importance of making sense of her psychotic experience for recovery: I was worried about these strange spirits and he 
Ouwehand, E., Wong, K., Boeije, H., Braam, A. Revelation, delusion or disillusion: subjective interpretation of religious and spiritual experiences in bipolar disorder. Mental Health Religion and Culture: 2014, 17(6), 615-628

(spiritual counsellor of the hospital) explained, that in Greek diabolos is the force that can sow unrest and actually can strike at places of chaos. That is exactly what I experience during psychosis. I am very confused then, that is my illness, it is in my genes. But because of the chaos in my head it could well be that a kind of diabolos starts to work in me so that I end up with macabre thoughts and demonic hate. From the moment I understood this, a lot more of the puzzle pieces of my life fell into place and I got more involved in the rehabilitation- movement... These questions, philosophical questions, are very important. I am convinced that if one does not find somebody who can help you with it, you continue to search for meaning and you can often notice that they come back in the next psychosis. (P5, New Age Spirituality) The different ways of giving meaning to experiences during mania and depression can be ranged from, on the one hand, a totally medical interpretation of the experiences and the rejection of them as genuine religious or spiritual, to, on the other hand, the rejection of the medical model in favour of a spiritual interpretation. P3, from an orthodox Protestant background judged his "mystical" experiences during mania to be illusory and a part of his illness. Whereas P10 considered her religious experiences during mania as being closely related to her spiritual development.

Her bipolar disorder was a necessary hurdle in this development from which she could learn (P10, New Age Spirituality). In most interviews, different explanatory models (Kleinman, 1988) coexisted and the participants used concepts from different linguistic fields.

\section{Cherishing of blissful experience}

Related to the issue of authenticity was the theme of cherishing the blissful experiences of the manic state. Because they were classified as so "fantastic", "happy" or other descriptions of similar purport, participants did not want to miss them. "Like addiction, first the high and afterwards the hangover", P3 commented. Some participants felt cut off from these experiences when using medication. Some participants showed an ambivalent attitude towards this issue. On the one hand, they reported restraint in talking about these happy experiences, either because they found it difficult to explain them to other people, or because they were afraid the experiences would be interpreted as a sign of an emerging mania. On the other hand, some participants mentioned the "seductiveness" of these experiences and were aware of the danger of overvaluing them. "I was curious", P10 (New Age Spirituality) explained, while looking back upon the time of the onset of bipolar disorder, more than 20 years ago. "I thought: how far can I go? The universe is infinite". In the course of her life, this attitude had proved to be unhelpful. In the interviews, cherishing blissful experiences could go together with increasing religious activity: prayer, reading, painting or writing down experiences, sometimes originating from a strong desire to record them.

\section{Spiritual practice as support in illness-management}

Practices like mindfulness/meditation, prayer, reading religious texts and (biographical) writing, or tangible objects were mentioned as supportive in illness management. P6 (New Age Spirituality) reported that she benefitted a great deal from mindfulness training and the works of Eckhart Tolle. It helped her in keeping a distance from negative thoughts during depression and judging more realistically what she was able to do during a week. For P9 (not religious), meditation helped him 
Ouwehand, E., Wong, K., Boeije, H., Braam, A. Revelation, delusion or disillusion: subjective interpretation of religious and spiritual experiences in bipolar disorder. Mental Health Religion and Culture: 2014, 17(6), 615-628

finding rest when his mind was fuzzy, especially in unsettling times like holidays. P7 (Protestant) mentioned "rituals and small tangible things" that helped her to keep balanced: To keep the consciousness of being grounded, I need small things I can touch, like a tattoo (small Celtic cross). I know it is always there. Sometimes when I'm in trouble or don't know how to go on, I grab my arm: you are never without the Trinity.

The Celtic spirituality helped her to live in balance with nature, the seasons, the earth and her body, an attitude she had missed in her religious upbringing. Several participants mentioned that keeping balance could implicate not being involved too much with religious experiences, but observing attention for spirituality in concrete, everyday life. They articulated this in terms of "grounding" and described themselves as "badly grounded", or their spiritual experience as "having no feet". P8 (Roman Catholic), with his predilection for mystical experiences considered gardening and going to church to meet other people as a healthy counterbalance to his mystical aspirations. He had once gone through an intense spiritual week in a monastery during which the coaches had not recognised his developing mania.

\section{Expectations for treatment}

An explicit wish emerged from most interviews to talk about spirituality and religion during treatment.

It varied from the need for a rough impression of one's religious background on the side of the mental health-care professional, so as to be able to bring it up when necessary, to the specific wish to talk about the authenticity of their religious experiences. P5 (New Age Spirituality) regretted that she had not been able to talk about the question that was bothering her during the past 20 years since she was familiar with her illness: How does one come from this gigantic shame for what one has thought during psychosis, this megalomania and all things that press you down to the understanding that what has happened could have a meaning. Also to the recognition it is not $100 \%$ your own fault and it is not only your own brains that produce all this.

She stated that it was not so easy to work it all out alone. Reading spiritual books could help, but could cause confusion as well. Some participants stressed the importance for mental health-care professionals to bring the subject forward on their own initiative. Many participants thanked us explicitly for the interview, some had prepared it thoroughly and expressed their hope that professionals in mental health care would develop a more positive attitude towards religion and spirituality.

Several participants mentioned a spiritual counsellor of the institute as helpful, others expected more support in these matters outside of mental health care, but considered it appropriate for professionals to refer to reliable spiritual counsellors. Some participants mentioned that, during hospitalisation, they had come into contact with the spiritual counsellor by coincidence.

They found it a pity that other professionals did not refer to them, or only as a last solution, when other therapies did not work out. In this case, the need of the client was answered, but no clear view on the relationship between spirituality and bipolar disorder was developed. A second point of criticism was the fragmentation of health care: each professional had his or her own territory as a result of which the patient did not feel treated from an overall view in which religion had a place as well. 
Ouwehand, E., Wong, K., Boeije, H., Braam, A. Revelation, delusion or disillusion: subjective interpretation of religious and spiritual experiences in bipolar disorder. Mental Health Religion and Culture: 2014, 17(6), 615-628

\section{DISCUSSION}

The objective of the current study was to obtain insights from clients diagnosed with bipolar disorder on how religious experiences related to the disorder were conceived. Participants mentioned more spiritual experiences during mania than during depression. Making sense of these experiences and considering their authenticity appeared to be an important issue for most participants.

This outcome is in line with the results of the Quality of Life study of Michalak et al. (2006) which indicated that religious clients struggle to disentangle "real" experience from hyper-religiosity.

The explanatory models participants in our study used, ranged from predominantly medical to exclusively spiritual. Several authors in the psychiatric literature have tried to clarify the overlap between psychotic and religious experiences. The question is raised as to whether current psychiatric practice takes into account the growth potential in psychotic experience (Johnson \& Friedman, 2008; Lukoff, 1985). In our study, two participants stressed that their religious or spiritual experiences marked a new stage of life, in spite of their occurrence during a psychotic or manic episode. In most cases medical and spiritual explanations coexisted and more doubt was felt about the exact character of the experiences, but participants stressed that the experiences had spiritual or existential implications that exceeded the pathology. Discernment between "healthy" and "pathological" experience only might not be sufficient in the case of long-lasting mental disorders, because clients ask for a more phenomenological or hermeneutical approach to their religious experiences.

Klapheck, Nordmeyer, Cronjäger, Naber, and Bock (2012) state that recovery from psychotic crisis depends on the ability to find meaning in the psychotic experience. Glas (2012) advocates the reintroduction of an existential vocabulary in psychiatry. This perspective in research and treatment and its possible effect on health outcomes needs more elaboration in our view.

Religious or spiritual practice was mentioned by many participants as supportive in illness management: mindfulness/meditation, prayer, reading religious texts and (biographical) writing, or tangible objects. Mindfulness/meditation was mentioned as being supportive by participants with and the one participant without a religious view of life, which was in line with the outcome of the study of Mitchell and Romans (2003). In their study, participants who practised religion in a non-organisational way were more likely to report that their faith supported them in illness-management than those who practised in an organisational way. In our study as well, private practice was more often mentioned as being supportive than organised ritual. Participants in our study expressed various wishes with regard to treatment. Attention for their religious background, exploration of the religious or spiritual experiences and their meaning with professionals during treatment, consultation about practices like mindfulness/meditation, cooperation between the spiritual counsellors of the institute or reference to reliable spiritual counsellors outside the institute were mentioned. The wish for support from mental health-care professionals in our study corresponds with the findings on treatment expectation that emerged from the research of Pieper and van Uden (2005) under Dutch Protestant and Roman Catholic outpatients with various mental disorders. Only one-third of the religiously affiliated clients were satisfied with the treatment with regard to religious aspects in their study. Mitchell and Romans (2003) observed a paradigm conflict between medical and spiritual advisors in their study. In the Dutch situation, Pieper and van Uden (2005) 
Ouwehand, E., Wong, K., Boeije, H., Braam, A. Revelation, delusion or disillusion: subjective interpretation of religious and spiritual experiences in bipolar disorder. Mental Health Religion and Culture: 2014, 17(6), 615-628

found that only a quarter of the clients judged a parish priest or minister more capable of dealing with problems that were related to religion or worldview. The majority of the participants considered the relationship between religion and mental health problems to be part of psychiatric treatment, and not of congregational pastoral care. According to the above study, therapists should be trained in these issues. In the sample of Pieper and van Uden outpatient-departments were without spiritual counsellors in the staff. In Dutch clinical settings, spiritual counselling is part of the offered care, as a voluntary support to standard treatment. The spiritual and existential dimension evoked by mental illness and what this means to individual clients in relation to religious or philosophical traditions, is the domain in which spiritual counsellors operate. From the perspective of the participants in our study, it does not seem to make much difference who pays attention to this dimension, as long as it is an integral part of treatment. They suggested that cooperation between spiritual counsellors allied to mental health-care-facilities and other professionals would be advisable to improve treatment.

The paradigm conflict between medical and spiritual advisors, mentioned by Mitchell and Romans (2003), was not mentioned in our study. This might be due to the fact that all participants were white Dutch, not belonging to an ethnic minority. The participants in our study were noticeably grateful for the opportunity to talk about their religious experiences. Some of them mentioned this explicitly to Wong as a psychiatrist and expressed their wish for more interest in spirituality in mental health care.

\section{Limitations of the study}

A limitation of the current study is that the participants did not represent the average client with bipolar disorder. Participants in this study should be regarded as well educated, and moreover well aware that they are part of a society that should be qualified as secularised. Therefore, other results might have been obtained in ethnic minorities with stronger religious affiliation with regard to the institutional aspect of religion, or in clients with bipolar disorder from western countries with higher levels of religious affiliation, such as the USA. The participants should therefore be regarded as clear examples of how clients struggle to make sense of their spiritual experiences during the development of their illness and what they expect of mental health care.

The fact that four participants were known by the first author, even though the contact had been some years before the interview, might have created bias in the interview results and therefore entail a weakness of the present study. On the one hand, it did give an easy access to these participants who would otherwise possibly have been more reluctant to talk about their spiritual experiences. On the other hand, it has probably led to participation of clients with a more than average affinity to religion. Most of them explicitly expressed their hope that the study would contribute to directing more attention to spirituality and religion in psychiatric treatment. A larger sample in future research should balance this possible weakness and gain more in-depth knowledge which could contribute to treatment guidelines, especially at the first onset of the disorder. In this study, religious experiences were explored. The claim of Klapheck et al. (2012) that making sense of psychotic experience is important for all clients and not only for religiously affiliated persons, can only be determined by large-scale cross-sectional research. Another limitation of the present study is that all participants had contact with mental health-care professionals of 
Ouwehand, E., Wong, K., Boeije, H., Braam, A. Revelation, delusion or disillusion: subjective interpretation of religious and spiritual experiences in bipolar disorder. Mental Health Religion and Culture: 2014, 17(6), 615-628

Altrecht. This study therefore does not clarify the question as to whether lack of attention for religion in treatment is a reason for non-compliance with therapy. In the study of Mitchell and Romans (2003), all participants indicated that they had encountered problems with conflicting advice between medical and spiritual advisors and one-third of the participants indicated problems concerning the use of medication on account of their religion.

\section{CONCLUSIONS}

In this study, religiously affiliated participants reported struggling with the interpretation of their spiritual experiences during manic and depressive states. Attention to this fact is desirable in treatment.

The euthymic state proves to be a good moment for reflection on the supportive or problematic role that religion plays in clients' lives with regard to bipolar disorder. For adequate counselling in existential and spiritual matters, cooperation between spiritual counsellors and other mental health-care professionals is advisable and more empirical research into helpful clinical interventions is needed.

Acknowledgements

We would like to acknowledge the assistance of Elsa Dawson and Elizabeth Harding with the English version of the manuscript.

\section{REFERENCES}

Altman, E. G., Hedeker, D. Peterson, J. L., \& Davis, M. (1997). The Altman Self-Rating Mania Scale.

Biological Psychiatry, 42, 948-955. doi:10.1016/S0006-3223(96)00548-3 Applebaum, P. S., Robbins, P. C., \& Roth, L. H. (1999). Dimensional approach to delusions: Comparison across types and diagnosis. American Journal of Psychiatry, 156(12), 1938-1943. http://ajp.

psychiatryonline.org/article.aspx?articleID=173853 Baetz, M., Boven, R., Jones, G., \& KoruSengul, T. (2006). How spiritual values and worship attendance relate to psychiatric disorders in the Canadian population. Canadian Journal for Psychiatry, 51, 654- 661. www.ncbi.nlm.nih.gov/pubmed/17052033 Baetz, M., Griffin, R., Bowen, R., \& Marcoux, G. (2004). Spirituality and psychiatry in Canada: Psychiatric practice compared with patient expectations. Canadian Journal of Psychiatry, 49(4), 265-271. www.

ncbi.nlm.nih.gov/pubmed/15147025 Biggerstaff, D. L. \& Thompson, A. R. (2008). Interpretative phenomenological analysis (IPA): A qualitative methodology of choice in healthcare research. Qualitative Research in Psychology, 5, 173-183. doi:10.

1080/14780880802314304 Boeije, H. R. (2010). Analysis in qualitative research. London: Sage.

Braam, A. W. (2009). Religion/spirituality in mood disorders. In P. Huguelet \& H. G. Koenig (Eds.), Religion/spirituality and psychiatry (pp. 97-113). New York, NY: Cambridge University Press.

Brocki, J. M., \& Wearden, A. J. (2006). A critical evaluation of the use of interpretative phenomenological analysis (IPA) in health psychology. Psychology \& Health, 21(1), 87108. doi:10.1080/ 14768320500230185 Cothran, M. M., \& Harvey, P. D. (1986). Delusional thinking in psychotics: Correlates of religious content.

Psychological Reports, 58, 191-199. doi:10.2466/pr0.1986.58.1.191 Creswell, J. W. (2007). Qualitative inquiry \& research design. London: Sage.

Dingemans, G. D. J. (1991). Als hoorder onder hoorders. Hermeneutische Homiletiek [If hearer under hearers. Hermeneutical Homiletics]. Kampen: Uitgeversmaatschappij J.H. Kok.

Fitchett, G., Burton, L. A., \& Sivan, A. B. (1997). The religious needs and resources of psychiatric inpatients. 
Ouwehand, E., Wong, K., Boeije, H., Braam, A. Revelation, delusion or disillusion: subjective interpretation of religious and spiritual experiences in bipolar disorder. Mental Health Religion and Culture: 2014, 17(6), 615-628

The Journal of Nervous and Mental Disease, 85, 320-326. PMID:9171809 Gallemore, J. L., Wilson, W., \& Rhoads, J. (1969). The religious life of patients with affective disorders.

Diseases of the Nervous System, 30, 483-487. PMID:5810555 Gerkin, C. V. (1984). The living human document. Nashville, TN: Abingdon Press.

Getz, G. E., Fleck, D. E., \& Strakowski, S. M. (2001). Frequency and severity of religious delusions in Christian patients with psychosis. Psychiatry Research, 103, 87-91. PMID:11472793 Glas, G. (2012). Filosofie van de psychiatrie [Philosophy of psychiatry]. In P. J. Verhagen \& H. J. G. M. van Megen (Eds.), Handboek psychiatrie, religie en spiritualiteit [Handbook of psychiatry, religion and spirituality] (pp. 63-75). Utrecht: De Tijdstroom uitgeverij.

Huguelet, P., \& Koenig, H. G. (2009). Introduction: Key concepts. In P. Huguelet \& H. G. Koenig (Eds.), Religion and spirituality in psychiatry (pp. 1-6). Cambridge: Cambridge University Press.

Johnson, C. V., \& Friedman, H. L. (2008). Enlightened or delusional? Differentiating religious, spiritual, and transpersonal experiences from psychopathology. Journal of Humanistic Psychology, 48(4), 505-527.

www.oxfordscholarship.com/.../acprof-9780198204 Klapheck, K., Nordmeyer, S., Cronjäger, H., Naber, D., \& Bock, T. (2012). Subjective experience and meaning of psychoses: The German Subjective Sense in Psychosis Questionnaire (SUSE).

Psychological Medicine, 42, 61-71. PMID:21733289 Kleinman, A. (1988). The illness narratives. New York, NY: Basic Books.

Kroll, J. \& Sheenan,W. (1989). Religious beliefs and practices among 52 inpatients in Minnesota. American Journal of Psychiatry, 146(1), 67-72. www.ncbi.nlm.nih.gov/pubmed/2912252 Kronjee, G., \& Lampert, M. (2006). Leefstijlen en zingeving [Lifestyles and meaning]. InW. B. H. J. van de Donk, A. P. Jponkers, G. J. Kronjee, \& R. J. J. M. Plum (Eds.), Geloven in het publieke domein [Believing in the public domain] (pp. 171-209). Amsterdam: Amsterdam University Press.

Lukoff, D. (1985). The diagnosis of mystical experiences with psychotic features. The Journal of Transpersonal Psychology, 17(2), 155-181. http://www.swedenborgiancommunity.org/files/Lukoff1985.pdf Michalak, E. E., Yatham, L. N., Kolesar, S., \& Lam, R. W. (2006). Bipolar disorder and quality of life: A patient-centered perspective. Quality of Life Research, 15, 25-37. www.ncbi.nlm.nih.gov/pubmed/ 16411028 Mitchell, L., \& Romans, S. (2003). Spiritual beliefs in bipolar affective disorder: Their relevance for illness management. Journal of Affective Disorders, 75, 247-257. PMID:12880937 Pesut, B., Clark, N., Maxwell, V., \& Michalak, E. (2011). Religion and spirituality in the context of bipolar disorder: A literature review. Mental Health, Religion \& Culture, 14, 785-796. doi:10.1080/13674676.

2010.523890 Pieper, J., \& van Uden, M. (2005). Religion and coping in mental health care. Amsterdam: Rodopi.

Rush, A. J., Trivedi, M. H., Ibrahim, H. M., Carmody, T. J., Arnow, B., Klein, D. N.,...Keller,M. B. (2003).

The 16-item Quick Inventory of Depressive Symptomatology (QIDS), clinician rating (QIDS_C), and self-report (QIDS-SR): A psychometric evaluation in patients with chronic major depression.

Biological Psychiatry, 54, 573-583. PMID: 12946886 Seyringer, M. E., Friedrich, F., Stompe, T., Frottier, P., Schrank, B., \& Frühwald, S. (2007). Die "gretchenfrage" für die psychiatrie. Der stellenwert von religion und spiritualität in der behandlung psychisch kranker [The "Gretchen question" for psychiatry. The set value of religion and spirituality in the psychological treatment sick]. Neuropsychiatrie, 21(4), 239-247. PMID:18082105 Spearing, M. K., Post, R. M., Leverich, G. S., Brandt, D, \& Nolen, W. (1997). Modification of the Clinical Global Impressions (CGI) Scale for use in bipolar illness (BP): The CGI-BP. Psychiatry Research, 73, 159-171. PMID: 9481807 Spilka, B., Hood, R.W. Jr., Hunsberger, B., \& Gorsuch, R. (2003). The psychology of religion. An empirical approach. New York, NY: Guilford Press.

Swinton, J., \& Mowat, H. (2006). Practical theology and qualitative research. London: SCM Press.

Woodhead, L., Heelas, P., Seel, B., Szerszynski, B., \& Tusting, K. (2005). The spiritual revolution. Why religion is giving way to spirituality. Malden, MA: Blackwell. 
Ouwehand, E., Wong, K., Boeije, H., Braam, A. Revelation, delusion or disillusion: subjective interpretation of religious and spiritual experiences in bipolar disorder. Mental Health Religion and Culture: 2014, 17(6), 615-628

\section{TABLES}

Table 1. Sample characteristics $n=10$.

\section{Characteristics}

Average age (years)

Sex

Women

Men

Civil status

Married/in a relationship

Single

Children (one or more)

Education

Higher education

Religious/philosophical studies

Original religion/spirituality

Protestant

Roman Catholic

Present religion/spirituality

New Age Spirituality

Protestant

Roman Catholic

Not religious

Medication

Using medication

Unknown

Average duration illness (years)
Number

\section{2}

6

4

6

4

3

10

5

6

4

4

4

1

1

9

1

13.7 
Ouwehand, E., Wong, K., Boeije, H., Braam, A. Revelation, delusion or disillusion: subjective interpretation of religious and spiritual experiences in bipolar disorder. Mental Health Religion and Culture: 2014, 17(6), 615-628

Table 2. Coding example: religious experiences (main code).

\begin{tabular}{|c|c|c|}
\hline Code & Subcode & Quote \\
\hline \multirow[t]{6}{*}{$\begin{array}{l}\text { Depressive } \\
\text { episode }\end{array}$} & Support & $\begin{array}{l}\text { Sometimes I feel at such moments, I call it the nail at the edge of } \\
\text { the well on which I can put my foot ... (P7) }\end{array}$ \\
\hline & $\begin{array}{l}\text { Absence/abandonment } \\
\text { by God }\end{array}$ & $\begin{array}{l}\text { When I am depressed, light is pretty absent, so I can't believe } \\
\text { very easily then that light exists. During depression I } \\
\text { experience the absence of God, I feel abandoned then, very } \\
\text { lonely (P6) }\end{array}$ \\
\hline & $\begin{array}{l}\text { Failure, guilt, } \\
\text { punishment }\end{array}$ & $\begin{array}{l}\text { Just because I love Him, I felt this failure so much the worse } \\
\text { (P3) }\end{array}$ \\
\hline & Devil, dark powers & $\begin{array}{l}\text {... during depression, I am afraid the devil really exists and that } \\
\text { I can have very bad experiences with it (P6) }\end{array}$ \\
\hline & Suicide & $\begin{array}{l}\text { No, I did not feel desolated, absolutely not. The moments I was } \\
\text { occupied with suicide I thought: then it will be finished in the } \\
\text { end and I will be there (with God EO), (P1) }\end{array}$ \\
\hline & Religious doubt & $\begin{array}{l}\text {... this emptiness is present. And I think my whole belief is } \\
\text { unsettled because you do not feel anything, you are totally } \\
\text { lonely and empty and cannot experience anything (P5) }\end{array}$ \\
\hline \multirow[t]{8}{*}{ Manic episode } & Vocation & $\begin{array}{l}\text { So I did not have a form of religious insanity, but I thought } \\
\text { something like "who knows what important message I have } \\
\text { for the world" (P10) }\end{array}$ \\
\hline & $\begin{array}{l}\text { Paranormal } \\
\text { experience, vision }\end{array}$ & $\begin{array}{l}\text { My world was divided in three spaces or levels. The terrestrial } \\
\text { level, the celestial level and an in-between level. And there } \\
\text { were light beings, that could move freely between the three } \\
\text { levels, they went up and down. And it was as if you could join } \\
\text { in with them, as if you were not so stuck to the ground (P7) }\end{array}$ \\
\hline & Connection & $\begin{array}{l}\text { I feel that I can see through the whole cosmos and understand } \\
\text { the whole world ... that I have insight in the structures behind } \\
\text { creation. It is a great pleasure to know the meaning of all } \\
\text { things (P8) }\end{array}$ \\
\hline & Presence God/Light & $\begin{array}{l}\text { I really felt God was there and He himself would tell me what to } \\
\text { say. That was a very special moment ( } \mathrm{P} 1)\end{array}$ \\
\hline & Fusion & $\begin{array}{l}\text { When I do not remain enough close to myself, I can become } \\
\text { someone else. That is what people usually do not understand, } \\
\text { that I can totally become the other (P10) }\end{array}$ \\
\hline & Mystical union & $\begin{array}{l}\text { I walked on the beach with my father, it was a clear night and I } \\
\text { pointed some constellations out to him. It gave me the idea: } \\
\text { you are very small, you are part of something much larger } \\
\text { than yourself. That is what I experienced very strongly (P3) }\end{array}$ \\
\hline & Time & $\begin{array}{l}\text { I: You said that during depression, you get caught up in time. } \\
\text { How is that during mania or psychosis? R: Yes, then you are } \\
\text { completely free from time. But it becomes ... but the real } \\
\text { religious experience is free from time (P8) }\end{array}$ \\
\hline & Deepest self & $\begin{array}{l}\text { I felt I went deep inside, I was not accessible at that moment. It } \\
\text { was as if I wiped out the last dust; the experience to be able to } \\
\text { start anew. That was the most important experience (P2) }\end{array}$ \\
\hline
\end{tabular}

